\title{
RELATO DE EXPERIÊNCIA DO PROCESSO GERENCIAL DO ENFERMEIRO SOB O OLHAR DO ACADÊMICO DE ENFERMAGEM
}

\author{
Luane de Oliveira Sena1; Adrina Dall Asta Pereira²
}

\section{RESUMO}

Objetiva relatar a experiência discente vivenciada durante o Estágio Curricular Supervisionado I, sobre a importância da gestão do enfermeiro, a partir da atuação do estudante em uma instituição hospitalar. Trata-se de um relato de experiência realizado durante a disciplina de estágio curricular supervisionado em enfermagem I, do Curso de Enfermagem da Universidade Franciscana, disciplina realizado no período de março a junho de 2021, em uma unidade cirúrgica de um hospital $100 \%$ SUS, localizado em Santa Maria-RS. O estágio supervisionado possibilita identificar que os profissionais precisam estar sempre se capacitando, uma vez que a falta de aperfeiçoamento, faz com que haja muitas possibilidades de erros. Estes, são mais comuns do que imaginamos, sendo que em diversos momentos foi levantado essa questão frente aos colaboradores. Desta forma, há necessidade de dar mais ênfase as ações educacionais para aperfeiçoar e preparar os colaboradores. Foi possível compreender melhor o lugar do enfermeiro assistencial dentro das unidades, assim como todo o processo de gestão da unidade, equipe e cuidados em saúde.

Palavras-chave: Educação Permanente; Enfermagem; Gestão.

Eixo Temático: Atenção Integral e Promoção à Saúde.

\section{INTRODUÇÃO}

Hospitais de ensino são estabelecimentos que realizam tanto assistência, gestão, processo de trabalho, quanto ensino e pesquisa ao mesmo tempo, e com isso possuem muitos desafios (SCHERER, et.al. 2018). Tanto a gestão e gerência quanto o processo de trabalho em saúde, especialmente na enfermagem, estão ligados ao modo de manejar a organização como um todo: pacientes, funcionários, unidade e suas necessidades. Para isso é necessário analisar, reconhecer e identificar as necessidades e fragilidades locais, ou seja, realizar um diagnóstico

\footnotetext{
${ }^{1}$ Acadêmico do Curso de Enfermagem - UFN. E-mail: senaluane@gmail.com

${ }^{2}$ Orientadora - Enfermeira - Doutora, Professora do Curso de Enfermagem - UFN. E-mail: adrianadallastapereira@gmail.com
} 
situacional e intervir buscando correções. Além destes, também é necessário planejar, prevenir, provir e controlar os recursos materiais e humanos para o bom funcionamento do serviço e desenvolver a gerência do cuidado dos pacientes (TENÓRIO, et.al. 2019). A conexão entre instituição de ensino e serviço de saúde proporciona ao estudante, um ambiente favorável ao ensino e aprendizagem, viabilizando 0 desenvolvimento das competências inerentes à profissão (RIGOBELLO et al., 2018).

O estágio supervisionado vem complementando o conhecimento teórico, permitindo que reconheçamos que não há enfermagem sem gestão, e não há gestão em saúde sem enfermagem. Em todos os momentos de tomada de decisão, identificação de problemas e busca por soluções está a enfermagem gerindo, bem como nos atendimentos singulares da enfermagem, onde há um olhar diferenciado sobre o paciente e suas necessidades, assim gerindo o cuidado.

Em inúmeros momentos pude perceber e/ou realizar o processo de trabalho e gestão em saúde, desde a avaliação de pacientes que não estavam aptos a receber alta, acompanhamento e reavaliação; reorganização de leitos visto que a unidade estava superlotada e alguns pacientes aguardavam na sala de espera para internação; conflitos entre equipe, organização e reorganização de escala de trabalho; encaminhamento de pacientes via gerente, entre outros. Todo o processo de gestão/gerencia vai muito de encontro com o processo de trabalho em saúde/enfermagem, sendo que um contempla o outro.

A partir disso, é importante a presença do enfermeiro nos quartos, avaliando e acompanhando todos os pacientes, entretanto, percebo que nem todos os dias é possível, pois muitas vezes as questões burocráticas de gerência e do processo de trabalho da unidade tomam um tempo excessivo dos enfermeiros, como reuniões, comissões, preenchimento de formulários etc., impedindo que os mesmos se façam presentes como gostariam, tendo assim que confiar na visão da equipe de enfermagem, que deve notificar ao enfermeiro qualquer alteração.

Nesse interim, o estágio supervisionado possibilita ao estudante um momento rico, cheio de oportunidades de aperfeiçoamento profissional diante de situações no gerenciamento e gestão dos serviços prestados, os quais possibilitam uma 
UUCACÃO, SAÚDE

ETECNOLOGIA

26 A 28 DE OUTUBRO DE 2021

construção efetiva entre todos os envolvidos nas etapas do cuidado de enfermagem e gestão, os quais são fundamentais para a formação do enfermeiro e para a qualidade da assistência prestada (OLIVEIRA; GRIBOSKI, 2018).

Tendo em vista o exposto acima, o estudo tem como objetivo relatar a experiência discente vivenciada durante o estágio curricular supervisionado I, sobre a gestão do enfermeiro, a partir da atuação do estudante em uma instituição hospitalar.

\section{METODOLOGIA}

O presente trabalho é de caráter descritivo, do tipo relato de experiência, realizado a partir da vivência discente no Estágio Curricular Supervisionado em Enfermagem I (ECS I) do Curso de Enfermagem da Universidade Franciscana (UFN), totalizando 150 horas. Realizado no período de maio a julho de 2021, no turno da manhã.

O local de realização do estágio foi em uma Unidade Cirúrgica pertecente a um Hospital de médio porte, que atende 100\% SUS em uma unidade cirúrgica. Atualmente a unidade recebe pacientes pré e pós cirúrgicos, contando com 15 leitos, sendo quartos semi-privativos com 2 a 3 leitos por quarto, subdivididos em masculino e feminino

As atividades desenvolvidas na unidade acabam por ser uma rotina, sendo as principais e mais comuns a admissão/internação de pacientes, Sistematização da Assistência de Enfermagem (SAE), anamnese e exame físico, preparo e orientações pré-operatórias, encaminhamento ao bloco cirúrgico, recepção de paciente pós cirúrgico, orientações e cuidados pós-operatórios, curativo em ferida operatória, orientações dos cuidados em domicílio, devolução de exames e alta hospitalar e administração de medicamentos.

\section{RESULTADOS E DISCUSSÕES}

A partir da proposta do ECS, inicialmente o estudante deve realizar um diagnóstico situacional do cenário, onde o mesmo é apresentado ao serviço e posteriormente identifica as especificidades do local bem como suas demandas. 
EDUCAÇÃO, SAÚDE

ETECNOLOGIA

26 A 28 DE OUTUBRO DE 2021

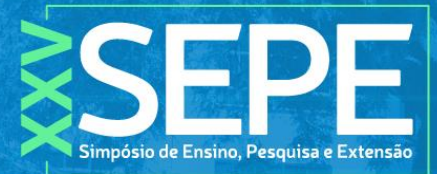

QUFN

Assim o estudante tem a oportunidade de atuar de forma participativa e empreendedora,na gestão do cuidado com o objetivo de agregar as equipes ao passo que desenvolve as competências e aprimora habilidades fundamentais à profissão.

Nesse sentido, o ECS possibilita ao graduando estabelecer uma identidade profissional pautada no conhecimento teórico científico, além de exercitar o alinhamento entre teoria e prática (RAMOS et al., 2018).

Em unidades hospitalares um dos procedimentos mais realizados são a administração de medicamentos, esta atividade é desenvolvida principalmente pelos técnicos em enfermagem, que devem preparar e administrar medicações com muita segurança, atentando a todos os cuidados para que não ocorra erros de administração COREN BA (2016).

Além dos cuidados no preparo e na administração, também é de extrema importância o aprazamento e checagem de horários nas prescrições, bem como as evoluções/anotações de enfermagem. O aprazamento e checagem garantem o cuidado do paciente e o respaldo legal dos enfermeiros e técnicos em enfermagem. De acordo com o um parecer do COREN BA (2016), os registros de enfermagem ajudam a na comunicação entre equipes, nos seus respectivos turnos, possibilitando o entendimento do que foi realizado com o paciente em todo o período.

Neste sentido, é importante que as checagens de medicações sejam feitas em conjunto com as evoluções/anotações de enfermagem, pois a prescrição é o documento mais prático para verificar as medicações administradas, e a partir do momento em que uma medicação for administrada e não checada, pode desencadear erros de medicação, podendo ser administrado duas vezes o mesmo medicamento.

O estágio supervisionado possibilitou identificar que erros como estes são mais comuns do que imaginamos, sendo que em diversos momentos foi levantado essa questão frente aos técnicos em enfermagem, cobrando pelas checagens nas prescrições e não somente anotação no sistema. A checagem se faz necessário para evitar erros de administração e em casos de a internação ser por meio de 
EDUCAÇÃO, SAÚDE

ETECNOLOGIA

26 A 28 DE OUTUBRO DE 2021

planos de saúde, é necessário a checagem como comprovação e restituição de gastos.

Outra questão gerencial percebida é a ausência de profissionais para trabalhar em dias que estão de escala, ou seja, avisos de última hora de que não comparecerão na unidade para trabalhar, levando a sobrecarga do resto da equipe. Sabe-se que é comum profissionais da enfermagem trabalharem em dois locais para obterem uma remuneração suficiente para suprir suas necessidades financeiras, o que torna o serviço exaustivo. Concomitante a isso, a sobrecarga de serviço quando faltam profissionais leva a estresse e desestimula o restante da equipe (SILVA; JULIANI, 2012).

Com base nas observações durante o estágio supervisionado, destaco essas como as maiores fragilidades encontradas: a não checagem de medicações administradas no prontuário e as faltas de profissionais em escala. Ambas as fragilidades foram conversadas pela enfermeira da unidade com sua equipe, e trabalhadas com a Educação Permanente, entretanto sem muito retorno por parte da equipe. No entanto, há necessidade continuar a observar a realidade do local para utilizar as temáticas necessárias, para que se possa transformá-la e após utilizar-se de aportes teóricos para qualificar a assistência prestada.

Salienta-se que nesse processo de aprender, a Educação Permanente apresenta-se como uma intervenção, com diversas ações que geram um treinamento, levando a reflexão e consequentemente capacitando e fortalecendo o trabalho em equipe (PINTO, 2016). Também a Educação Continuada resulta de um processo que envolve treinamenos e capacitação dos profissionais, buscancando revisões e atualizações, assim mantendo os atendimentos aos pacientes o mais eficiente e seguro possível (SARDINHA, et al., 2013).

Sabemos que a ciência e saúde estão em constante atualização, e neste sentido, as equipes também devem estar atualizadas. Quanto a isto, reconheço que - Hospital se esforça para manter seus colaboradores atualizados, estimulando e levando os mesmos palestras, orientações e capacitações de temas importantes e necessários. Não só gestores do hospital, mas também os enfermeiros gestores das 
unidades, que capacitam suas equipes sempre que necessário sobre temáticas que necessitam ser revistas e aperfeiçoadas pela equipe.

É valido mencionar a importância de possuir uma equipe competente, que possui conhecimentos básicos para identificar qualquer anormalidade ou alteração e notificar a enfermeira. Nem sempre se obtém uma boa comunicação entre equipe, podendo haver inclusive conflitos entre os mesmos. Neste sentido, observa-se que um bom líder tem uma maior facilidade em mediar esses conflitos, sendo um exemplo a ser seguido e sempre escutado pela equipe.

A liderança se tornou uma competência necessária na enfermagem, pois torna o profissional capaz de influenciar sua equipe, o que repercute diretamente na qualidade dos serviços e nos relacionamentos enquanto equipe (AMESTOY et al., 2017). Neste âmbito, foi possível identificar na pratica a diferença de um enfermeiro líder comparado a um enfermeiro apenas gestor, e as interferências disso na prática.

O enfermeiro líder é ouvido com atenção, respeitado e seguido. Além disso, o líder serve de exemplo para o restante da equipe, que acabam seguindo seus passos, orientações e modo de agir. E quando necessário também é ouvinte, sempre levando em consideração tudo que é referido pela equipe, assim como suas necessidades. Neste sentido, durante os estágios pode-se visualizar e aprender muito sobre como dirigir e coordenar uma equipe, que ainda é uma das questões mais difíceis dentro das unidades hospitalares.

\section{CONCLUSÃO}

Ao decorrer deste período de estágio foi possível compreender melhor o lugar do enfermeiro assistencial dentro das unidades, assim como todo o processo de gestão da unidade, equipe e cuidados em saúde, assim como as maiores fragilidades encontradas e dificuldades de para a enfermagem.

Tive o prazer de conviver e aprender diretamente com profissionais enfermeiros qualificados, e assim obter novos conhecimentos que só a prática nos possibilita, permitindo sair da teoria e reconhecer a realidade da saúde pelo SUS, com seus benefícios e fragilidades. Ao fim do estágio consigo perceber meu amadurecimento, refletindo diretamente na minha autonomia profissional, 
autoconfiança na atuação e perceber a importância do processo de gestão realizado pelo enfermeiro.

\section{REFERÊNCIAS}

AMESTOY, S.C.; TRINDADE, L.L.; SILVA, G.T.R.; SANTOS, B.P.; REIS, V.R.S.S.; FERREIRA, V.B. Liderança na enfermagem: do ensino ao exercício no ambiente hospitalar. Escola Anna Nery, v. 21, n. 4, 2017.

CONSELHO REGIONAL DE ENFERMAGEM DA BAHIA. PARECER COREN - BA NNo 014/2016. Assunto: Padrão correto de checagem de medicação. Setembro 2016. PINTO, H.A. Política Nacional de Educação Permanente em Saúde. A educação permanente em saúde e as redes colaborativas. Porto Alegre: Rede UNIDA; p.2365, 2016.

RAMOS, T. K. et al. Estágio curricular supervisionado e a formação do enfermeiro: atividades desenvolvidas. Revista de Enfermagem da UFSM, Santa Maria, v. 8, n. 1, p. $59-71,2018.2$ Disponível em: https://periodicos.ufsm.br/reufsm/article/view/28124/pdf. Acesso em: 22 set. 2021. SARDINHA, P.L.; CUZATIS, G.L.; DUTRA, C.T.; TAVARES, C.M.M.; DANTAS, C.A.C.; ANTUNES, C.E. Educación permanente, continuada y de servicio: desvelando sus conceptos. Enferm Glob. v. 12, n. 29, p. 307-22, 2013.

SCHERER, M.D.A.; CONILL, E.M.; JEAN, R.; TALEB, A.; GELBCKE, F.L.; PIRES, D.E.P.; JOAZEIRO, E.M.G. Desafios para o trabalho em saúde: um estudo comparado de Hospitais Universitários na Argélia, Brasil e França. Ciência \& Saúde Coletiva, v. 23, n. 7, p. 2265-2276, 2018. DOI: 10.1590/141381232018237.08762018

SILVA, L.C.P.; JULIANI, C.M.C.M. A interferência da jornada de trabalho na qualidade do serviço: contribuição à gestão de pessoas. Rev. Adm. Saúde, v. 14, n. 54, p. 11-18, 2012.

TENÓRIO, H.A.A.; SOUZA, I.B.; GOMES JUNIOR, E.L.G.; SANTOS, R.F.E.P.; CORREIA, D.S.; VIANA, L.S.; MARQUES, E.S.; BRANDÃO, T.M.; Gestão e gerenciamento de Enfermagem: perspectivas de atuação do discente. Revista de 
EDUCAÇÃO, SAÚDE

ETECNỎLGIA

26 A 28 DE OUTUBRO DE 2021

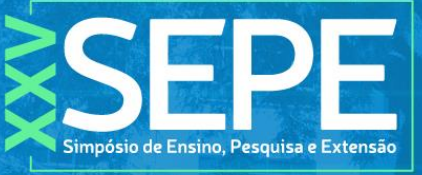

TRABALHO COMPIETO

Enfermagem UFPE online. V. 13, p. 240-535, 2019. DOI:

https://doi.org/10.5205/1981-8963.2019.240535

OLIVEIRA, W. G., GRIBOSKI, C. M. O estágio supervisionado na formação do enfermeiro revisão integrativa. Trabalho de conclusão de curso. 2018. 